\title{
TRANSFORMASI STRUKTUR SOSIAL DALAM PEMANFAATAN RPTRA DHARMA SUCI JAKARTA UTARA
}

\author{
Sugeng Wahjudi \\ Program Studi Ilmu Komunikasi, Universitas Bunda Mulia \\ Diterima 8 Maret 2019 / Disetujui 25 Maret 2019
}

\begin{abstract}
The focus of RPTRA's activities reflects services for children and community services to become a community center that functions as a center of interaction and is used by all elements of society from various age groups. This research is an advanced stage of previous research on the relationship of RPTRA managers. The communication network that is built into the use of the RPTRA can be utilized for the development of institutional components that are socio-economic. By using Max Webber's instrumental rationality approach, this study can identify the social changes that have been formed. This study will provide a description relating to changes in knowledge, attitudes and actions of the people who use RPTRA. Changes that arise from individual RPTRA users (mothers) are driven by actions based on value orientation. Their actions involved in activities at RPTRA were not driven by instrumental orientation (to obtain economic benefits) or traditional orientation (because of tradition - driven by the authority structure) In general it can be concluded that RPTRA was able to take a good role. RPTRA is not a material space that distributes materials / materials to make a transformation of the social structure of society (change in social action). The results of the study indicate the formation of rationality in the use of RPTRA if it is associated with user social actions and program activities that put RPTRA as a center in building social relations for their local communities and social change.
\end{abstract}

Keywords: RPTRA, communication network, social change, social actions.

\begin{abstract}
ABSTRAK
Fokus kegiatan RPTRA mencerminkan layanan bagi anak dan layanan masyarakat menjadi wadah community center yang berfungsi sebagai pusat interaksi dan dimanfaatkan oleh seluruh elemen masyarakat dari berbagai kelompok umur. Penelitian ini adalah tahap lanjutan dari penelitian sebelumnya tentang relasi para pengelola RPTRA. Jaringan komunikasi yang terbangun dalam pemanfataan RPTRA dapat dimanfaatkan untuk pengembangan komponen kelembagaan yang ada secara sosial ekonomi. Dengan menggunakan pendekatan rasionalitas instrumental dari Max Webber, penelitian ini dapat mengidentifikasi perubahan sosial yang terbentuk. Penelitian ini akan memberikan deskripsi yang berkaitan dengan perubahan pengetahuan, sikap dan tindakan masyarakat pengguna RPTRA. Perubahan yang muncul dari individu pengguna RPTRA (ibu-ibu) di dorong oleh tindakan yang berdasar pada orientasi nilai. Tindakan mereka terlibat dalam aktivitas di RPTRA tidak di dorong oleh orientasi instrumental (untuk memperoleh keuntungan ekonomis) ataupun orientasi tradisional ( karena tradisi - digerakan oleh struktur otoritas) Secara umum dapat disimpulkan bahwa RPTRA mampu mengambil peran yang baik. RPTRA bukan ruang material yang mendistribusikan materimateri/kebendaan untuk membuat transformasi struktur sosial masyarakat (perubahan dalam tindakan sosial). Hasil penelitian menunjukkan pembentukan rasionalitas dalam pemanfaatan RPTRA jika dikaitkan dengan tindakan sosial pengguna dan program kegiatan menempatkan RPTRA dapat menjadi sentra dalam membangun relasi sosial bagi komunitas lokal mereka serta perubahan social.
\end{abstract}

Kata Kunci: RPTRA, jaringan komunikasi, perubahan sosial, tindakan social.

*Korespondensi Penulis:

e-mail:swahjudi@bundamulia.ac.id 


\section{PENDAHULUAN}

Kegiatan RPTRA Dharma suci, tidak hanya terkait kegiatan sosial seperti olah raga, belajar dan bermain. Aktivitas yang bernilai ekonomi juga digerakkan dengan berbagai kegiatan yang melibatkan institusi perguruan tinggi. Hasil Survey pendahuluan yang dilakukan peneliti memperoleh deskripsi RPTRA merupakan pusat pembelajaran, pelatihan, pengembangan dan rujukan dari berbagai kelompok kegiatan. Ruang Publik Terpadu Ramah Anak (RPTRA) sekaligus tempat dan/atau ruang terbuka yang memadukan kegiatan dan aktivitas warga dengan mengimplementasikan 10 (sepuluh) program Pokok Pemberdayaan dan Kesejahteraan Keluarga untuk mengintegrasikan dengan program Kota Layak Anak.

Keberadaan RPTRA yang diresmikan oleh Gubernur DKI Basuki Tjahaya Purnama setahun yang lalu pada 06 April 2017, memiliki aktivitas yang cukup dinamis dengan keterlibatan yang sangat baik. Fokus kegiatan RPTRA mencerminkan layanan bagi anak dan layanan masyarakat menjadi wadah community center yang berfungsi sebagai pusat interaksi dan dimanfaatkan oleh seluruh elemen masyarakat dari berbagai kelompok umur.

Penelitian ini adalah tahap lanjutan dari penelitian sebelumnya tentang relasi para pengelola RPTRA. Jaringan komunikasi yang terbangun dalam pemanfataan RPTRA dapat dimanfaatkan untuk pengembangan komponen kelembagaan yang ada secara sosial ekonomi. Jaringan komunikasi yang ada dapat mengatasi masalah hambatan diseminasi informasi dan sumbatan masalah komunikasi yang terjadi baik dalam pengelolaan RPTRA . Hasil Penelitian sebelumnya menunjukkan pola jaringan komunikasi dalam konteks pemanfaatan RPTRA jaringan komunikasi berbentuk $Y$ dan Roda. Klik dalam bentuk Y pada jaringan komunikas ini tampak bahwa kelompok menjadi sentralistik dengan menempatkan sesorang menjadi poros. Individu yang berada di Poros akan mengendalikan alur informasi yang tersebar diantara 2 orang lainnya yang berkomunikasi. Berdasarkan penelitian sebelumnya mengenai jaringan komunkasi dalam pemanfaatan RPTRA menghasilkan temuan bahwa para Pengurus PKK tingkat RW memiliki keterhubungan yang sangat baik satu sama lain, yang memungkinkan akttivitas RPTRA berjalan dengan baik.

Pengembangan RPTRA sebagai kawasan ruang publik dan ramah anak sebagai kebijakan dan program pemerintah provinsi berpotensi memiliki masalah jika ruang publik tersebut menjadi obyek dari kebijakan dan program. Bergantinya pimpinan daerah Propinsi DKI Jakarta berpeluang kebijakan pengelolaan RPTRA tersebut tidak bisa berhasil dan dapat dikembangkan secara berkelanjutan (sustainable).

Pengembangan dan optimalisasi fungsi RPTRA sebagai ruang publik di Kelurahan Pejagalan sebagai proses transformasi yang berlangsung di masyarakat bisa jadi tidak berjalan secara alami dan asli. Penelitian ini penting dilakukan untuk memahami bagaimana perubahan yang terjadi pada masyarakat sasaran atau pengguna aktivitas RPTRA. Informasi ini menjadi sangat penting untuk mengetahui pertimbangan rasionalitas mereka dalam kegiatan RPTRA, sekaligus dapat menjadi gambaran atas feedback mereka.

\section{METODE PENELITIAN}

Unit analisa penelitian ini adalah subjek pengelola RPTRA dan masyarakat sasaran pengguna dan kegiatan RPTRA, yaitu anak remaja dan ibu-ibu. Penelitian ini menggunakan desain penelitian kualitatif karena lebih menekankan pada proses-proses yang berlangsung serta mencari jawaban atas pertanyaan yang diberi makna oleh peneliti. Dalam penelitian lanjutan dari penelitian relasi dan peran aktor dalam hubungan komunikasi dalam pengelolaan RPTRA ini, diarahkan untuk melihat bagaimana implementasi proses desiminasi informasi mengenai kegiatan pengguna RPTRA sebagai obyek pengamatan. Dengan menggunakan 
pendekatan rasionalitas instrumental dari Max Webber, penelitian ini dapat mengidentifikasi perubahan struktur sosial yang terbentuk. Penelitian ini akan memberikan deskripsi yang berkaitan dengan perubahan pengetahuan, sikap dan tindakan masyarakat pengguna RPTRA .

\section{Prosedur Penelitian}

Prosedur penelitian ini terdiri dari beberapa tindakan metodologis terutama dalam proses :

\section{Pengumpulan Data}

Jenis data yang diumpulkan terdiri dari data prime dan sekunder. Data primer bersumber dari observasi berupa pengamatan langsung dilapangan, dan wawancara mendalam dengan subyek yang diteliti atau informan. Sedang Data sekunder diperoleh dari datadata dokumentasi, kajian literatur yang berfungsi sebagai pendukung data primer.

\section{Teknik Analisa Data}

1. Reduksi data yang terkumpul dengan tujuan untuk penajaman, penggolongan, dan memilah data yang dilakukan selama penelitian berlangsung

2. Menyusun matrik data penelitian dan menyajikan teks dalam bentuk naratif

3. Fokus Group Disccusion (FGD), pada anggota masyarakat khususnya anak remaja dan ibu-ibu yang menjadi sasaran kegiatan RPTRA Dharma Suci

4. Penarikan kesimpulan dan verifikasi data melalui peninjauan ulang atas catatan lapangan

\section{HASIL DAN PEMBAHASAN}

Hasil Transformasi Dan Rasionalitas Pemanfaatan RPTRA. Penelitian lanjutan mengenai pemanfaatan RPTRA Dharma Suci ini bertujuan untuk mengetahui bagaimana implementasi dari desiminasi informasi dari hasil kajian jaringan komunikasi kepada masyarakat sasaran kegiatan RPTRA. Aktivitas RPTRA tentu saja melibatkan peran serta masyarakat sasaran. Pada gilirannya kajian penelitian ini dapat mendesripsikan bagaimana perubahhan pengetahuan sikap, dan tindakan sasaran kegiatan RPTRA khusunya ibu ibu di wilayah RPTRA Dharma Suci.

Fokus penelitian mengenai jaringan komunikasi dan transformasi sosial ini dimaksudkan untuk memperoleh gambaran realitas desiminasi informasi dan implementasi kegiatan-kegiatan yang dikelola RPTRA mampu menyentuh secara merata dalam menghasilkan transformasi sosial sebagai bentuk perubahan pada pengetahuan, sikap dan pola perilaku masyarakat dalam pemanfaatan RPTRA

Proses pengelolaan RPTRA secara oragnisasi berkaitan erat kondisi sosial atau budaya lingkungan sosial atau masyarakat yang menjalankan aktivitas nafkah seharihari. Ruang publik RPTRA sebagai Infrastruktur sosial terdiri dari proses kelembagaan mengalami penyesuaian sejalan dengan perubahan pola jaringan komunikasi sosial mereka dengan masyarakat. Aktifitas RPTRA awalnya mengelola ruang publik ini secara top down dengani arahan kelurahan dan penawaran kegiatan dari pihak eksternal, seperti kampus, kantor kedinasan seperti kesehatan dan pendidikan kebudayaan.

Tabel 1. Kegiatan-Kegiatan Eksternal

\begin{tabular}{|l|l|l|}
\hline No & Institusi & Kegiatan \\
\hline 1 & $\begin{array}{l}\text { UNIVERSITAS } \\
\text { BUNDA MULIA }\end{array}$ & $\begin{array}{l}\text { Keterampilan } \\
\text { Penyuluhan }\end{array}$ \\
\hline 2 & $\begin{array}{l}\text { DOKTER MATA } \\
\text { RS.DUTA } \\
\text { INDAH }\end{array}$ & $\begin{array}{l}\text { Sosialisasi } \\
\text { Katarak }\end{array}$ \\
\hline 3 & $\begin{array}{l}\text { DINAS } \\
\text { PEMADAM } \\
\text { KEBAKARAN }\end{array}$ & Pelatihan \\
\hline 4 & BKKBN & Pelayanan KB \\
\hline 5 & MC.DONALD & $\begin{array}{l}\text { Lomba } \\
\text { mewarnai }\end{array}$ \\
\hline 6 & $\begin{array}{l}\text { PKK } \\
\text { KELURAHAN }\end{array}$ & $\begin{array}{l}\text { Pertemuan } \\
\text { Rutin }\end{array}$ \\
\hline 7 & P2TP2A & $\begin{array}{l}\text { Penyuluhan } \\
\text { kekerasan } \\
\text { pada anak }\end{array}$ \\
\hline
\end{tabular}

Sumber : Data Observasi diolah 
Nilai positif dari kegiatan di atas adalah penambahan pengetahuan ibu-ibu yang menjadi sasaran utama kegiatan RPTRA. Pengetahuan yang diterima dari berbagai macam kegiatan tersebut mewarnai pengetahuan ibu-ibu pengguna RPTRA Berikut pernyataan ibu Ani :

Saya senang mengikuti kegiatan di RPTRA, saya mendapat pengetahuan tentang kegiatan kegiatan dari pemerintah. Saya jadi tahu bagaimana menjaga kesehatan anak dan keluarga

Pendapat Ibu Ani diperkuat oleh penjelasan yang diberikan oleh ibu Popon yang juga terlibat dalam kegiatan RPTRA yang menyatakan :

Betul pak, saya juga mendapat wawasan, pengetahuan saya juga bertambah terutama untuk mendidik anak. Saya juga menjadi tahu kegiatan-kegiatan kelurahan. Kita juga sering ngomongin dengan sesama ibu ibu mengenai hal-hal yang dihadapi dalam mendidik anak.

Pengetahuan-pengetahuan yang ditransformasikan dalam berbagai kegiatan tersebut menjadi penting dan menambah wawasan dan pengetahuan umum. Dari sisi perolehan informasi, nilai tambah yang diperoleh adalah pengetahuan terhadap program-program dari kelurahan (pemerintah) yang berhubungan dengan kesehatan dan kesejahteraan masyarakat Mereka juga memperoleh nilai positif terhadap perkembangan prestasi maupun aktivitas bermain bagi anak yang aman dan nyaman.

Motif tindakan sosial dalam memanfaatkan ruang publik RPTRA ini dapat merupakan tindakan rasional yang mengacu pada nilainilai dalam sebagian masyarakat memegang teguh pada aspek manfaat yang berhubungan dalam kehidupan bermasyarakat. Peranan sosial ibu-ibu dalam keluarga dan lingkungan masyarakat dituntut mampu bermasyarakat dalam menjaga anak-anak maupun keluarga. Dalam interview melalu diskusi kelompok kecil, peneliti mendapatkan informasi sebagi berikut :
1. Ketersediaan ruang publik RPTRA serta pemanfataanya dapat meningkatkan pengetahuan dan wawasan

2. Memperoleh nilai positif terhadap perkembangan prestasi maupun aktivitas bermain bagi anak yang aman dan nyaman

3. Relasi bertambah luas dan suasana hati menjadi nyaman karena bertambahnya teman dan dapat saling berbagi.

4. RPTRA menjadi ruang relasi yang dapat mengubah mindset terhadap lingkungan sosial, serta menjadi sarana untuk membangun relasi sosial dan solidaritas diantara mereka

Penambahan pengetahuan dalam partisipasi ibu-ibu pengguna RPTRA dalam perpektif tindakan sosial merupakan proses pembentukan rasionalitas seiring dengan perubahan pola pikir mereka tentang keberadaan RPTRA. Rasionalitas yang mendasari tindakan ibu-ibu pengguna RPTRA dipengaruhi oleh rasionalitas yang terdapat dalam program kegiatan rasionalitas komunitas mereka di lingkungan sosialnya. Rasionalitas nilai (value) yakni sifat rasionalitas yang berorientasi nilai. Tindakan berdasarkan rasionalitas nilai (value-rational action) didasarkan lebih dominan atas kepentingan idealistik (ideal interest). Deskripsi ini sesuai dengan hasil pertikan interview dalam diskusi kelompok kecil dari nara sumber ibu Parwanti (ibu rumah tangga)

Saya aktif mengikuti kegiatan RPTRA, selain tidak bekerja saya perlu menambah pengetahuan. Melalui kegiatan di RPTRA dan bersosialisasi dengan ibu-ibu yang lain dapat menjadi tempat untuk ngobrol dan diskusi mengenai kegiatan-kegiatan bersama. Bahkan kami sekarang punya kegiatan yang ditanggung bersama ibu ibu yaitu les tari. Kami yang menanggung biaya pelatih, kami hanya pinjam tempat saja di RPTRA Dharma Suci

Dalam hal ini orientasi ibu-ibu pengguna RPTRA, keterlibatan mereka tidak sekedar memenuhi undangan atau informasi dari pengelola. Kegiatan-kegiatan bersama yang terbentuk diantara ibu-ibu menunjukkan 
pentingnya membangun relasi dan bersosialisasi dalam kehidupan sosial mereka. Menurut peneliti terdapat kepentingan idealistik pada mereka dengan mengacu pada pemenuhan atau pencapaian rasionalitasnya yang berorientasi nilai. Komitmen terhadap nilai-nilai sangat kuat sehingga pertimbangan-pertimbangan instrumental mengenai kegunaan (utility), efesiensi, dan sebagiannya menjadi tidak relevan. Menurut Weber tindakan rasional yang berorientasi nilai, merupakan tindakan yang dilakukan dalam sistem sosial dengan membasiskan tingkah lakunya pada nilai-nilai dasar dalam masyarakat.

Berdasarkan temuan tersebut di atas, secara umum, potensi usaha untuk mengembangkan fungsi RPTRA lebih dari arena bermain sangat terbuka. Aktivitas RPTRA tidak hanya terbatas dari program yang berangkat dari kelurahan atau dari pihak eksternal. Kegiatan yang berangkat secara bottom up dari warga pengguna sangat layak untuk dapat dikembangkan, berkaitan dengan optimalisasi fungsi RPTRA sebagai ruang publik. RPTRA dapat dioptimalkam sebagai sentra untuk aktualisasi gagasan atau aktivitas dari masyarakat untuk meningkatan kualitas kehidupan sosial. Hasil diskusi yang dilaksanakan oleh peneliti dengan nara sumber, diperoleh informsi bahwa partisipasi mereka dalam berbagai kegiatan RPTRA menunjukkan tingginya dukungan mereka dengan akivitas ruang publik ini. Berikut penuturan dari Ibu Ani :

Saya merasa kegiatan RPTRA ini sangat bermanfaat bagi saya dan anak saya. Saya bisa bersilaturahmi dan bersosialisasi dengan teman-teman dan pihak kelurahan. Saya bisa mendikusikan dengan teman-teman dan juga para penyuluh mengenai masalah-masalah keluarga, terutama mengenai pendidikan anak. RPTRA ini juga menjadi tempat yang aman bagi anak saya dan yang lain untuk bermain

Mengacu dari pemaparan Ibu Ani, dapat mengisyaratkan bahwa mereka memperoleh manfaat positif dari keberadaan RPTRA tersebut. Memperkuat pernyataan ibu Ani mengenai pemanfaatan RPTRA ibu Yanti justru memberikan pendapat yang lebih komprehensif

Kalo saya pak, saya terdorong mengikuti kegiatan di RPTRA ini karena selain mengisi waktu luang, saya dapat bertemu dengan teman-teman sesama ibu-ibu. Saya juga menjadi lebih terbuka wawasan dan pikiran dalam mendidik anak dan mengatur rumah tangga. Saya juga sering membagi kemampuan saya dalam memasak. Hubungan dengan ibu-ibu juga sangat baik sehingga kami lebih kompak bergaul

Aktivitas kegiatan di ruang publik ini menjadi berkembang berangkat dari inisatif pengguna dan tidak sekedar berangkat dari program yang bersifat top down. Tanggapan masyarakat terhadap program dan aktivtas di RPTRA meskupun relatif beragam tetapi menggambarkan bagaimana tindakan komunikasi positif. Rasionalitas tindakan mereka , menurut peneliti menunjukkan pergeseran sistem sosial dengan terbentuknya kelompok sosial yang mengembangnkan nilai-nilai kebersamaan. Menurut Ibu Eka bahkan menyampaikan bahwa ibu-ibu tidak sayang jika harus mengeluarkan uang iuran untuk membuat kegiatan bersama untuk amak-anak mereka. Berikut petikannya :

Kami iuran lho pak, buat ngajari guru les, kami juga iuran ketika anak-anak pentas ke tempat lain. Pengelola RPTRA hanya memberikan tempat ini untuk latihan. Tapi kami berterima kasih pada pengurus karena menyedikan tempat bagi anak-anak bermain dan berlatih. Bahkan kami juga membuka group whats App. Informasi mengenai RPTRA dan kegiatan bersama ibu-ibu ya melalui WA ini pak

Hasil temuan peneliti dari hasil observasi dan diskusi kelompok dengan mereka menjelaskan bahwa mereka mampu membangun kelompok dalam distribusi kegiatan-kegiatan

Sebagian dari ibu-ibu ini tampil sebagi gate keeper pada kegiatan di RPTRA yang antusias dalam mengadopsi berbagai informasi, pengetahuan yang diperoleh dari kegiatan-kegiatan di RPTRA Dharma Suci. Salah satu alasan ibu-ibu untuk mengadopsi 
berbagai hal dalam partispasi mereka justru bukan alasan yang bersifat keuntungan materia (instrumentally), namun lebih didasarkan pada rasa kenyamanan dalam bersosialisai dan terbukanya pikiran mereka (mind set) dalam menghadapi problemproblem. Pada tataran kelompok ini tindakan rasional yang muncul adalah rasionalitas value. Rasionalitas ini menduduki peranan penting dalam struktur komunikasi sosial. Tindakan sosial para ini didasarkan dominan berorientasi pada pilihan-pilihan yang bersumber dari tindakan yang bersifat normatif dan memiliki tujuan atas dasar pertimbangan aktivitas mereka berkaitan dengan pengumpulan informasi, dan kemampuan mengembangkan nilai-nilai sosial.

Program dan kegiatan pada RPTRA memiliki dampak yang signifikan terhadap perubahan pola fikir dan tindakan rasional ibu-ibu yang terlibat dalam kegiatan tersebut. Berikut dalah tabel tindakan rasionalitas berkaitan dengan pemanfaatan RPTRA

Tabel 2. Hasil Analisis Jaringan dan Transformasi Sosial

\begin{tabular}{|l|l|ll|l|}
\hline $\begin{array}{l}\text { Analisis } \\
\text { Jaringan }\end{array}$ & $\begin{array}{l}\text { Hasil } \\
\text { Sosio } \\
\text { gram }\end{array}$ & $\begin{array}{l}\text { Transformasi } \\
\text { Sosial }\end{array}$ & $\begin{array}{l}\text { Rasiona } \\
\text { litas }\end{array}$ \\
\hline $\begin{array}{l}\text { Bentuk } \\
\text { Jaringan }\end{array}$ & $\begin{array}{l}\text { Interl } \\
\text { ock } \\
\text { perso } \\
\text { nal } \\
\text { netwo } \\
\text { rk }\end{array}$ & $\begin{array}{l}\text { - } \\
\text { aiferensi } \\
\text { asi peran }\end{array}$ & $\begin{array}{l}\text { Rasiona } \\
\text { Nilai- } \\
\text { nilai } \\
\text { Kelompo } \\
\text { nilai } \\
\text { (Value) }\end{array}$ & \\
& & $\begin{array}{l}\text { k/sosial } \\
\text { Pengetah } \\
\text { uan }\end{array}$ & \\
& Bentu & & \\
k Y & & & \\
\end{tabular}

Sumber : Analisis Data

Pembentukan rasionalitas dalam pemanfaatan RPTRA jika dikaitkan dengan tindakan sosial pengguna dan program kegiatan menempatkan RPTRA dapat menjadi sentra dalam membangun relasi sosial bagi komunitas lokal mereka serta perubahan sosial Proses tindakan rasionalitas yang berlangsung dalam alam pikiran merupakan proses mental dan pertimbangan berbagai basis rasionalitas sebagai pengaruh faktor internal dan eksternal sebelum pada pengambilan keputusan dan pemilihan tindakan yang paling cocok dalam menghadapi perubahan.

\section{SIMPULAN}

Keberadaan RPTRA Dharma Suci di kelurahan Pejagalan Jakarta Utara mampu menghasilkan transformasi sosial yang ditandai dengan perubahan pengetahuan, sikap dan tindakan sosial dalam membangun relasi. Dorongan untuk terlibat secara aktif adalah nilai manfaat RPTRA bagi edukasi dan tempat bermain anak, bersosialisasi, mengetahui program program pemerintahan desa, refresing dan relaksasi, tempat share dan problem solving, dan mempererat relasi / solidaritas. Perubahan dalam diri individu dalam pemanfaatan RPTRA

1. Dalam aspek pengetahuan berupa bertambahnya wawasan tentang pengetahuan umum, pendidikan anak, lingkungan, dan program-program pemerintah

2. Pada aspek sikap, individu memiliki pemahaman mengenai solidaritas dan responsifpada persoalan lingkungan maupun kehidupan sosial

3. Pada aspek tindakan, individu memiliki tingkat partisipatif yang tinggi dalam kegiatan sosial

Perubahan yang muncul dari individu pengguna RPTRA (ibu-ibu) di dorong oleh tindakan yang berdasar pada orientasi nilai. Tindakan mereka terlibat dalam aktivitas di RPTRA tidak di dorong oleh orientasi instrumental (untuk memperoleh keuntungan ekonomis) ataupun orientasi tradisional ( karena tradisi digerakan oleh struktur otoritas) Secara umum dapat disimpulkan bahwa RPTRA mampu mengambil peran yang baik. RPTRA bukan ruang material yang mendistribusikan materi-materi/kebendaan untuk membuat transformasi struktur sosial masyarakat (perubahan dalam tindakan sosial)

Analisis jaringan komunikasi pengurus dalam pengelolaan RPTRA dan kaitannya dengan rasionalitas tindakan 
masyarakat pengguna memberikan deskripsi terjadinya proses perubahan sosial memperlihatkan eksistensi dan perubahanperubahan pada individu yang saling berinteraksi dalam sistem sosial mereka.

\section{DAFTAR PUSTAKA}

Fiedler, Klaus .ed. 2007. Social Communication. Psychologie Press, Madison Avenue

Forsyth, T. 2003. Critycal Political Ecology. The politic of enviromental Science, Routledge, London and New york.

Jennifer, Golbeck. 2013. Analyzing the Social Web. Boston: Elservier.

Nasution Z, 2002, Komunikasi Pembangunan, Pengenalan Teori dan Penerapannya, Edisi Revisi, Cetakan keempat, Jakarta, Raja Grafindo Persada

Nee V., 2005, The New Institualism in Economics and Sosiology, Princenton University Press and New York : The Russel Sage Foundation

Ritzer, George and Douglas J Goodman, 2010, Teori Sosiologi: Dari Teori klasik sampai Perkembangan Mutakhir Teori Sosial Postmodern, Yogyakarta, Kreasi Wacana

Serveas, 2002. Communication for Development : One Word, multiple cultures, Second Printing, Cresskill, New Jerjey, Hamton Press Inc.

Soekanto, 2014, Sosiologi Suatu Pengantar, Jakarta, Raja Grafindo Persada

Weber, Max, 1978, Economy and Society, Universit of California Press Berkeley, and Los Angeles, California 